\title{
Caregiving, Disability and Gender in Academia in the Time of COVID-19
}

Monica C. Schneider ${ }^{1}$, Leigh Graham², Abigail S. Hornstein ${ }^{3}$, Katie Jo LaRiviere ${ }^{4}$, Kathleen M. Muldoon $^{5}$, Stephanie L. Shepherd ${ }^{6}$, Rachel Wagner ${ }^{7}$

${ }^{1}$ Miami University (Oxford, OH), ${ }^{2}$ Harvard T. H. Chan School of Public Health and Ariadne Labs, ${ }^{3}$ Wesleyan University, ${ }^{4}$ Mount Angel Seminary, ${ }^{5}$ Midwestern University (Glendale, AZ), ${ }^{6}$ Auburn University, ${ }^{7}$ Ithaca College (Ithaca, NY)

\author{
Author Note \\ Monica C. Schneider https://orcid.org/0000-0002-6948-4520 \\ Leigh Graham https://orcid.org/0000-0002-4984-5894 \\ Abigail S. Hornstein https://orcid.org/0000-0002-9172-0411 \\ Kathleen M. Muldoon https://orcid.org/0000-0001-5024-4183 \\ Stephanie L. Shepherd https://orcid.org/0000-0001-5125-9571 \\ We have no conflicts of interest to disclose. \\ Correspondence concerning this article should be addressed to Monica Schneider, 349 E
} High St, Rm 218, Oxford, OH 45056 Email: schneimc@miamioh.edu 


\begin{abstract}
We are a community of academic women who parent children with disabilities. In this essay, we draw on our experiences as mother-scholars and our collective experiences as an affinity community to demonstrate how the university system often ignores us as whole people, fragmented between our worlds as academics and as carers. We offer this integrated systems-ofcare model as a counternarrative to the dominant emphasis on hyperindividualism in the neoliberal U.S. university system.
\end{abstract}

Keywords: Academic Mothers, Caregiving, Disability, COVID 


\section{Caregiving, Disability and Gender in Academia in the time of COVID-19}

We are a community of academic women who parent children with disabilities. In this essay, we draw on our experiences as mother-scholars and our collective experiences as an affinity community to demonstrate how the university system often ignores us as whole people, fragmented between our worlds as academics and as carers. ${ }^{1}$ Below, we offer an integrated systems-of-care model as a counternarrative to the dominant emphasis on hyperindividualism in the neoliberal U.S. university system.

The pervasive political culture of individualism in U.S. society has enabled a persistent under-funding of support for people with disabilities (PWD). ${ }^{2}$ Accordingly, PWD and their caregivers face substantial challenges accessing necessary services. As our children's caregivers, we must balance work and caregiving demands more so than parents of typically developing children; some of us expect to do so into our children's adulthood. In addition to teaching, research, and service, our typical week includes time visiting doctors, coordinating therapy appointments, battling insurance companies, and meeting the complex emotional, mental, physical, and sensory needs of our children. Helping our children succeed requires a village that we often construct from the ground up, including hiring, scheduling, coordinating, and compensating providers and other caregivers. A lack of policy support forces us to confront these challenges in isolation; the social stigma associated with disability often forces us to confront these challenges in secret.

\footnotetext{
${ }^{1}$ Even when viewed as whole persons with complex and multidimensional needs and potential contributions, we nevertheless find lacking a deeper consideration of the communities or systems we each need to thrive. Trauma research has provided useful definitions of the concept of the "whole person," while medical research has recently made calls for its use in treatment (Bazaz, 2021; Ferrell et al., 2020).

${ }^{2}$ We use both person-first and identity-first language in this essay, in recognition of the diversity of preference for framing disability in the disability community. Style guides provide no firm guidance, although people with disabilities and its acronym, PWD, appear to be commonly used. We acknowledge and respect the variety of individual preferences of PWD, including those of our own children, while struggling with an appropriate linguistic solution to a heavily-debated topic.
} 
Our caregiving labor includes challenging the ableism our children experience. We often negotiate the terms of special education goals and supports with school personnel and lawyers under Section 504 and the Individuals with Disabilities in Education Act (IDEA) ${ }^{3}$ the latter of which has been described as "effectively the only parentally enforced federal law on the books" (McLaughlin, 2020). ${ }^{4}$ Both IDEA and Section 504 use a deficit frame, as opposed to a neurodiversity frame (Understood For All Inc., 2021), that defines our children by what they cannot achieve compared to their typically developing peers (Dinishak, 2016; Harry and Klinger, 2007; Perry, 2021). In advocating for the legal rights of our children, we find ourselves also educating others on our children's strengths and intrinsic value as whole people themselves.

In academia, we regularly encounter social and institutional structures that lack norms of inclusion, flexibility, and diversity that would better support all caregivers. Feminist scholars of science studies argue that the academy is constructed and organized around the archetype of the male scientist (Keller, 1995). Gender is thus a key variable shaping productivity and success through the "signals, resources and rewards" that are conferred in workplaces that code scientific inquiry as a masculine enterprise (Fox, 1991; Keller, 1995). This gendered construct of science also influences acceptance of alternative embodiments of "scientist": an NSF task force found that "attitudes are the single most significant barrier faced by individuals with disabilities pursuing careers in science and engineering," and that STEM faculty hold the most negative attitudes (Burgstahler, 1994). Given the disproportionate caregiving demands that pattern our

\footnotetext{
${ }^{3}$ Michener (2018, p 85), refers to this kind of negotiation as "particularistic resistance," which she defines as "when policy beneficiaries take oppositional action in response to administrative decisions that threaten their access to valuable resources."

${ }^{4}$ Individualized Education Plans (IEP) and Section 504 plans are enacted under different legal jurisdiction and protect different rights depending upon the student's educational needs. While IEPs define specialized education plans required for students with disabilities under the IDEA, 504 plans protect them from discrimination based on their disability (see the US Department of Education website). IDEA is an unfunded federal mandate that is partially funded by individual states at varying rates (e.g., McLaughlin 2020).
} 
career pathways and the isolation that comes from societal ableism, our self-concept as academic mothers of children with disabilities includes a heightened awareness of our intersectional identities. Our lived experiences thus counter academic and corporate cultures of hyperindividualism.

\section{Caregiving, Disability and Pandemic Inequities}

The COVID-19 pandemic has magnified health and social inequities for PWD. As a result, many of us have partially or completely lost our carefully built support networks. Our children disproportionately require 1:1 adult attention, some up to 24-hours a day, and some experience heightened anxiety and depression. Due to the increased risk of mortality and morbidity from COVID-19 for some of our children, our households have lost respite care, inclusive youth activities, and childcare. Given social distancing requirements, some organizations on which we have previously relied now refuse to accommodate children with disabilities needing adult support due to COVID-19 safety restrictions. In addition to greater health risks from COVID-19 exposure, the pandemic modalities of PK-12 education have also involved increased risk of academic and social-emotional regression for students with disabilities. Many alternative schooling and community arrangements, such as pods, are exclusionary by design. Federal and state laws that mandate inclusion in public school rarely extend to extracurricular activities.

Crisis schooling and child care thus involves material trade-offs for working mothers to fill the academic and therapeutic gaps left by the loss of the school- and community-based teams that work directly with our children. Many of us feel as though there is no end to work, since we have added working hours on evenings and weekends, while during the traditional STEM core business hours we juggle the demands of home and work. For others, we have reduced our 
workload through paid or unpaid time off, depending on our employer-based benefits. For all of us, we have had to forego professional opportunities as our household caregiving demands exponentially increased.

We find university responses wanting. Few of our institutions reduced expectations for quality and quantity of production of research and teaching (and in some cases, teaching loads increased). When expectations for productivity were adjusted, they were negotiated on a case-bycase basis. Yet such an approach renders invisible the systemic nature of this problem in the academy and ultimately sacrifices the needs of academic-mothers. Policies and decisions have prioritized the needs of, first, the workplace, and then children, over the mothers who serve both.

Some institutions recommend faculty use Care.com or similar services to hire someone to provide child care, with modest subsidies. However, these clearinghouse services do not guarantee access to specialized medical or behavioral care from an experienced caregiver, and the out of pocket cost for such care may be prohibitive. Furthermore, the health risks involved in allowing an additional person in the household bubble often outweigh any benefits of additional care. Not least, screening and hiring appropriate caregivers requires significant labor that typically falls on mothers (Raley et al., 2015).

For those of us whose universities require in-person teaching, we face the untenable risk that having a medically fragile child may not qualify us to work remotely. Without a caregiving exemption from teaching in-person, our only recourse may be unpaid leave. Overall, in pursuing accommodations the onus is on PWD and their caregivers to navigate a siloed bureaucracy built without accommodations. Critically, this individualistic approach in which every person fends for themselves to solve the disruptions caused by this pandemic means our families are not viewed as part of interconnected systems. The pandemic has laid bare how our children's rightful 
accommodations and support necessitate workplace accommodations and social support for their caregivers too.

\section{Solutions}

The pandemic has exposed and exacerbated the academy's lack of attention to whole people who are part of complex support systems. Diversity, equity and inclusion (DEI) initiatives are incomplete without attending to disability, beginning with an equity audit of policies, departments, curricula, and learning spaces to root out ableism. Concrete steps should include hiring and retention of PWD, learning programs to support students with disabilities, expansive workplace policies to support caregiving for dependents with disabilities, and equity measures built into assessment and performance reviews. As part of their inclusion advocacy efforts, universities might consider partnering with local programs for children (especially before- and after-school programs and summer camps) to ensure inclusion for children with disabilities. Strategically, when institutions participate in networked systems of support for disabled

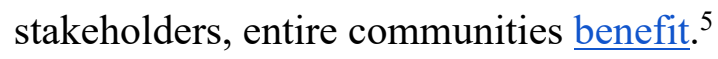

University policies should be put in place now for a safer, more equitable future. An essential first step is policy permitting remote work - including teaching - if an employee has caregiving responsibility for a high-risk person. Flexibility is essential for us; many of us have benefitted from exemptions in institutional service, priority in course scheduling, serving on committees where work can be done after hours, and release from being present during traditional working hours. All faculty should receive some pandemic-related career supports, including course reduction, fewer teaching preps, research leave, sabbaticals, time added to the tenure clock (if desired), no-cost extensions on spending internal and external funds, access to

\footnotetext{
${ }^{5}$ For example, testimonials from before the pandemic by non-disabled students at the University of Oregon and Colorado State University attest to the wider benefits of community inclusion of PWD.
} 
university-sponsored writing circles and/or supportive teaching groups. Caregivers of children with disabilities should be included in high priority groups given access to these resources. Wellness supports should be expanded, not curtailed, with free or subsidized access to exercise and mental health options online, in-person, and at a variety of times, including set-aside sessions for vulnerable groups. Direct funds to households and partnerships with community organizations to cover child and respite care for children with disabilities could be transformative for academic caregivers' productivity and wellbeing. Budget considerations for pandemic relief and assistance for academic caregivers could allocate funds from pay cuts taken by senior administrators earlier in the pandemic.

Finally, given the pandemic disruptions we have described, universities should offer more than just tenure clock extensions to address pronounced gender inequities in research output: adequate allowances must be made to pre-pandemic review, tenure, and promotion expectations. Universities could mandate that promotion and tenure committees account for pandemic delays, make clear to external reviewers how to review files appropriately, and follow guidance from accrediting bodies or membership organizations (e.g., NAS, NASEM, AAUP, etc.). Many institutions have workload documents for post-tenure faculty that increase or decrease teaching loads depending on research productivity, which need adjustment for postpandemic life. We intend this partial list of solutions to spur universities to engage with families to design supports that accommodate caregiving in ways that root out ableism and gender inequity.

As the pandemic recedes, our households will be focused on reconstructing the support networks our children need to thrive. Like their peers around the world, our children have been adversely affected by the closures and restrictions imposed during the pandemic. As a result, 
some of our children will now need a more expansive or intensive support network than previously. This is a challenge likely to be exacerbated by increased demand on already scarce therapeutic and health services due to rising mental health needs among children and young adults due to COVID-19 (McCance-Katz, 2020). We urge university communities to reframe their understanding of disability, from an individualistic notion of a disabled person to the recognition of disability as a networked phenomenon with systemic impact. As we emerge from the pandemic, we have an opportunity to work collectively to name and address the lingering health effects of COVID-19 that have touched so many of our families, including those with typically developing children or those caring for other kin. We offer our experience as mothers of children with disabilities to demonstrate how integrated systems-of-care affect us as whole people and advocate for destigmatized systemic supports originating in higher education that accommodate not just the employee but their household and the broader community. Such supports are, indeed, a community value and a sine qua non for inclusiveness. Without a reorientation toward an integrated, systems-of-care model, we continue to risk the loss of significant research contributions, particularly from already marginalized members of the academic community. $^{6}$

\footnotetext{
${ }^{6}$ While this paper was under review we learned of a paper by Ahn et al. (2021) with similar ideas but complementary and different recommendations.
} 


\section{References}

Ahn, S. J. (Grace), Cripe, E. T., Foucault Welles, B., McGregor, S. C., Pearce, K. E., Usher, N., \& Vitak, J. (2021). Academic Caregivers on Organizational and Community Resilience in Academia (Fuck Individual Resilience). Communication, Culture and Critique, tcab027. https://doi.org/10.1093/ccc/tcab027

Bazaz, J. (2021). Whole Person, Whole Community, Whole World: Approaches to Trauma on a Global Scale: Review of Integrated Care for the Traumatized: A Whole-Person Approach, by Ilene A. Serlin, Stanley Krippner, and Kirwan Rockefeller. Rowman \& Littlefield, 2019, 222 pp. Reviewed by Joelle Bazaz, Buffalo, NY, USA.

Burgstahler, S. (1994). Increasing the representation of people with disabilities in science, engineering, and mathematics. Information Technology and Disability, 1(4), 4.

Dinishak, J. (2016). The Deficit View and Its Critics. Disability Studies Quarterly. 36(4). https://dsq-sds.org/article/view/5236/4475

Ferrell, B. R., Handzo, G., Picchi, T., Puchalski, C., \& Rosa, W. E. (2020). The urgency of spiritual care: COVID-19 and the critical need for whole-person palliation. Journal of pain and symptom management, 60(3), e 7-e11.

Fox, M. F. (1991). Gender, environmental milieu, and productivity in science. In H. Zuckerman, J. R. Cole, \& J. T. Bruer (Eds.), The outer circle: Women in the scientific community (p. 188-204). W W Norton \& Co.

Harry, B. and Klinger, J. (2007). Discarding the Deficit Model. Improving Instruction for Students with Learning Needs, 64, 16-21.

Keller, E. F. (1995). Gender and science: Origin, history, and politics. Osiris, 10, 26-38.

McCance-Katz, E. F. (2020). The National Survey on Drug Use and Health: 2019. Substance Abuse and Mental Health Services Administration. https://www.samhsa.gov/data/sites/default/files/reports/rpt29392/Assistant-Secretarynsduh2019 presentation/Assistant-Secretary-nsduh2019 presentation.pdf

McLaughlin, J.M. (2020, August). Most states fail education obligations to special needs students: So, what else is new? USA Today. https://www.usatoday.com/story/opinion/voices/2020/08/08/disability-rights-states-failobligation-special-needs-students/3318292001/ 
Michener, J. (2018). Fragmented democracy: Medicaid, federalism, and unequal politics. Cambridge University Press.

Perry, D.M. (2021, March). I shouldn't have to dehumanize my son to get him support. The Nation. March 22/29, 2021.

Raley, S., Bianchi, S. M., \& Wang, W. (2012). When do fathers care? Mothers' economic contribution and fathers' involvement in child care. American Journal of Sociology, $117(5), 1422-59$.

Understood For All Inc. 2021, March 25). Neurodiversity: What you need to know. Understood. https://www.understood.org/en/friends-feelings/empowering-your-child/building-onstrengths/neurodiversity-what-you-need-to-know 